\title{
Pregnancy outcomes and the use of two standards to assess adequacy of maternal body mass index in early gestation - CORRIGENDUM
}

\section{F. Mardones, P. Rosso, L. Villarroel, J. Bacallao, A. Dominguez, A. Passi, I. Rojas, M. Farias and P. Margozzini}

doi:10.1017/S204017441500714X, published by Cambridge University Press, 9 September 2015.

First published online 28 September 2015

In the Discussion section of the above article, the sentence:

The RM chart may be also used in many developing countries around the world, because in this chart, short and tall women are recommended to gain proportionally more and less weight, respectively, than average height women.

Should have read:

The RM chart may be also used in many developing countries around the world, because in this chart, short and tall women are recommended to gain proportionally less and more weight, respectively, than average height women.

\section{Reference}

Mardones F, Rosso P, Villarroel L, et al. Pregnancy outcomes and the use of two standards to assess adequacy of maternal body mass index in early gestation. Journal of Developmental Origins of Health and Disease. Published online by Cambridge University Press, 9 September 2015, doi:10.1017/S204017441500714X. 